\title{
Lethal Weapon in the Hands That Heals-Mobile Phone in Hospitals
}

\author{
Dr.A.Muruganathan,M.D ${ }^{1}$, Dr.C.Manokaran,M.D². Dr.T.Ravikumar, M.D ${ }^{3}$., \\ Dr.P.Malini,M.D ${ }^{4}$., Dr.P.Saravanan,M.D. ${ }^{5}$ dr.Sopna Jothi,M.D., ${ }^{6}$ \\ ${ }^{\text {I}}$ Emeritus Professor The Tamil Nadu Dr.Mgr Medical University \\ ${ }^{2}$ Prof.Of Medicine,manakkulavinayakar medical college Hospital pondichery \\ ${ }^{3}$ Prof and Hod of medicine Govt.Medical College And Esi Hospital, coimbatore \\ ${ }^{4}$ Asst prof of microbiology, Govt.Medical College And Esi Hospital, coimbatore \\ ${ }^{5}$ Asst Prof of medicineMadurai Medical College,Madurai \\ ${ }^{6}$ Asst Profof medicine Govt Theni Medical College, Theni
}

\begin{abstract}
Introduction: Mobile phones have become one of the most indispensable accessories of professional and social life, worldwide being easily accessible, economical and user-friendly Reports from Western nations have suggested that mobile phones are more often dirtier than toilet seats, (as toilet seats are often disinfected). toilet seats usually contained three different types of bacteria but mobile phones on an average housed some 1012 different types of fungi and bacteria.,

In U.S. hospitals hospital acquired infections cause 1.7 million infections per year and are associated with approximately 100,000 deaths. It is estimated that one third of these infections could be prevented by adhering to standard infection control guidelines

Aim of study: This study was conducted to investigate the level of bacterial contamination of mobile phones in most important wards of various tertiary care medical college hospitals in south India

Materials and methods: This original research study was carried out during a period of March 2017 to April 2017 A total of160mobile phones of the doctors working in various wards in tertiary care hospitals in the state of Tamilnadu and pondicherry were tested for their bacterial contamination. The examined mobile phones were randomly collected from departments: laboratory, ICU, Post operative ward and triage area .(as many hospitals ban the use of cell phones in side operation theatres they are excluded from the study) A questionnaire was used for data collection of all the relevant information on tested mobile phones. Oral consents were obtained from all individuals whose mobile phones were included in the present study.

Collection of samples: Samples from mobile phones were collected using sterile cotton swabs. Each swab was first moistened with sterile peptone water and was rotated over the surface of both sides of the tested mobile phone together with the keypad in non touch screen phones. and screens in touch phones. All swabs were immediately streaked (surface spread) over the surface of blood and MacConkey's agar plates.

Results: The current work revealed that the majority of isolated bacterial contaminants were mixed with more than one organism

Conclusion: Doctors and healthcare staff working in critical areas as intensive care units (ICUs) and post operative units are highly exposed to micro-organisms. These mobile phones used by them often become carriers and may serve as vectors and spread microorganisms, as our mobile phones are cumbersome to clean. We even rarely make an effort to disinfect them. As a result, these devices have the potential for contamination with various bacterial agents It is estimated that one third of these infections could be prevented by adhering to standard infection control guidelines
\end{abstract}

\section{Introduction}

Mobile phones are becoming an important means of communication among doctors and other health care workers (HCWs) in hospitals where hospital-associated infections (HAI) are prevalent. Global burden of HAI is on the rise and contributes significantly to morbidity and mortality of the patients. HCW use mobile phones in hospital halls, laboratories, intensive care units and operating rooms. During every phone call the mobile phone come into close contact with strongly contaminated human body areas with hands to hands, and hands to other areas like mouth, nose and ears. mobile phones act as perfect habitat for microbes to breed, especially in high temperature and humid conditions, HCWs' mobile phones may serve as reservoirs of microorganisms that could be easily transmitted from the mobile phones to the HCWs' hands and therefore facilitate the transmission of bacterial isolates from one patient to another in different hospital wards 
The question of concern is how to use the mobile phones sensibly, getting their benefits and minimizing their risks. Another point of view argues that, if mobile phones are used carelessly in surgical words or intensive care units (ICU), they may act as a source of infection to patients while handling them, such as during dressing of surgical wounds. Besides, there are no guidelines for disinfection of mobile phones that meet hospital standards.

In this study we investigated the rate of bacterial contamination of mobile phones among HCWs employed in our tertiary health care teaching hospital and compared it with personal mobile phones of non-HCWs (control group).

\section{Results}

The current work revealed that the majority of isolated bacterial contaminants were mixed with more than one organism. It has been found that all mobile phones tested from the laboratory (98\%) yielded mixed organisms, followed by $70 \%$ from triage area.68\% from post-operative wards On the other hand, $56 \%$ of the tested mobile phones from ICU revealed only one (single) isolate.

\begin{tabular}{|l|l|l|}
\hline $\begin{array}{l}\text { ITYTE OF } \\
\text { ORGANISM }\end{array}$ & $\begin{array}{l}\text { NUMBER OF } \\
\text { CFULPHONFS }\end{array}$ & PERCENTAGE \\
\hline CoNS & 70 & 43.75 \\
\hline MRSA & 12 & 7.5 \\
\hline MSSA & 12 & 7.5 \\
\hline Srept viridance & 13 & 8.12 \\
\hline Baciillus spp & 15 & 9.37 \\
\hline Deptheriod spp & 9 & 5.62 \\
\hline Enterocoscus spp & 9 & 5.62 \\
\hline Acinetobacter & 5 & 3.12 \\
\hline Psaidoenanas spp & 7 & 4.37 \\
\hline Salimonella spp & 3 & 1.87 \\
\hline Candida spp & 5 & 3.12 \\
\hline & 160 & \\
\hline
\end{tabular}

\section{TYPE OF ISOLATES FROM THE CELL PHONES}

of the $29 \%$ cell phones which were recorded to be cleaned by their owners, $72 \%$ yielded more than one organism. It has been also noted that the majority of individuals enrolled in the present study reported that they perform hand hygiene $(\mathrm{HH})$ practices $(137 / 160)$, of these $76 \%$ grew more than one organism from their cell phones.Considering the present results, it seems that cell phones and stationery could be the sources for transmission of hospital acquired infections to the patients. Also, since there is no particular guideline for handling the cell phones inside ICUs, their increasing use could be a health concern. Being used very widely and their importance for HCWs, restriction or deletion from ICUs cannot serve as a practical solution. Therefore, it is recommended that the ICU personnel be more careful and attentive to infection control precautions such as strict hand washing before entering ICU, regular hygiene before and after each patients touch, regular hand hygiene before and after mobile touch, daily decontamination of cell phone and stationery used by them, and avoiding the use of shared stuffs including stethoscope and penlight for different patients. In addition, developing respective guidelines and instructions for cleaning and decontaminating of the cell phones to be followed in ICUs, could be very helpful.

\section{Discussion}

The constant handling of mobile phones by users in hospitals makes it an open breeding place for transmission of microorganisms, as well as health care-associated infections (HAIs).In U.S. hospitals, they cause 1.7 million infections per year and are associated with approximately 100,000 deaths. It is estimated that one third of these infections could be prevented by adhering to standard infection control guidelines Mobile phones since they are carried in almost all human environments from the kitchen to the public transport harbour a larger diversity of micro-organisms. These microbes grow well on the sweat and grime left on the phones as humans carry them around.

In Pune, Yogesh S Shouche and his team from the Microbial Culture Collection group of the NCCS collected samples from 27 mobile phone screens and they were able to isolate 515 different bacterial types and 28 different fungi. 
The WHO said, "antibiotic resistance is growing, and we are fast running out of treatment

\section{Health hazards of mobile phones \#1. Cancer}

As reported by the World Health Organisation (WHO), mobile phones emit radiofrequency (RF) fields a 1000 times greater than what is emitted from base stations. It's obvious that this increased emission is likely to have some adverse effect on health of users. It suggests that development of brain tumour due to mobile use may take at least 20-25 years. And no one has really used a mobile phone for that long.

\section{Health hazards of mobile phones \#2. Sleep disorders}

Somehow night-time has always been favourite among regular chatting and gossiping freaks. But do you know that's the main reason why you are sleep deprived? Several studies have concluded this. which found that high mobile phone use was associated with sleep disorders. Major contributing factors to interrupted sleep pattern are getting awakened in the middle of the night due to mobile rings and vibration and increased use of mobiles post-evening until midnight.

\section{Health hazards of mobile phone \#3: Increased accident-risk}

Whether you're an iPhone, flip phone or a Blackberry user, the chances that you check your phone aggressively while travelling is undoubtedly higher. Be it while driving or while crossing the road, mobile phone can be a potential distraction. According to the WHO, we now have a lot of research showing an increased risk of traffic accidents with mobile usage (3-4 times greater).

\section{Health hazards of mobile phone \#4: Heart problems:}

Radiation from cell phones is not only associated with cancer but also with chronic diseases like heart problems mobiles, contribute to abnormalities in heart function. Results reported

\section{Health hazards of mobile phone \#5: Infertility:}

Beware men! Your phone can even make you infertile. As of now there's enough evidence to show that mobile phone radiation decreases sperm count in male rats. To identify whether the same holds true in humans, Wdowiak A and colleagues carried out a research which revealed that the group of men who used mobile phones had a decreased sperm cell count in their semen, leading to infertility.

Health hazards of mobile phone \#6: Hearing impairment:

Today, every alternate person on the street has earphones plugged in. But that's not the only reason why hearing loss is increasing in youth and adults. Your mobile radiation is an additional factor that's making you deaf. Studies report that long-term exposure to electromagnetic (EM) field from cell phones contributes to reducing hearing function. A study by Oktay MF and Dasdag S showed that people who attended phone calls for approximately 2 hours every day were at a higher risk of impaired hearing compared to those: who moderate users (10-20 mins) ${ }^{[5]}$.

Health hazards of mobile phone \#7: Eye strain; A lot of people use their mobiles to read e-books, do web surfing, etc apart from texting. When you do so, the glaring screen and small font size put a lot of strain on your eyes, especially if you're reading in the dark. Mobile devices have a smaller screens so you tend squint or open up your eyes wide open and blink lesser number of times. This can cause dry eyes, irritation and reddening.

Health hazards of mobile phone \#8: Skin allergies: Mostmobile phones have a typical metallic sheen to make them look more attractive. Such phones contain potential skin allergens like nickel, chromium and cobalt which cause cell phone dermatitis

Health hazards of mobile phone \#9: : Stress: The general desperate nature of people to be available 24/7 on their mobiles is responsible to their exponentially increasing stress levels

Health hazards of mobile phone \#10. Infections: How many of you use your phones in the restroom? Here's a good reason why you shouldn't. Cell phones not only serve as a home for your valuable data but also carry millions of infectious organisms. A study found that mobile devices are highly contaminated with organisms from fecal origin. They are a niche for several germs like E.coli (known to cause vomiting and diarrhea) and Staphyloccocus aureus (known to cause skin infections).

\section{Implications on Nosocomial Infections}

The rise of the use of mobile phones has surprisingly important implications in the microbiology and medical communities, most notably in the area of nosocomial infections. While some hospitals have banned them for this reason, mobile phone use is still relatively commonplace, even in operating rooms . Mobile phones, as well as other more documented items such as surgical equipment, stethoscopes, and clothing can act as a reservoir for bacterial growth or contamination. These items can then act as potential vectors, transferring bacteria onto susceptible patients through indirect-contact transmission. However, while many of these items are subjected to very high hygienic standards, standard cleaning procedures or even guidelines for the use of mobile 
phones in hospitals have yet to be established. Studies have shown a correlation between isolated bacterium found on health care workers' hands and their respective mobile devices, demonstrating the cross-contamination potential of mobile phones in the hospital environment. Furthermore, there is also the risk of further transmitting nosocomial pathogens outside of the hospital if health care workers use the same cell phone for personal use.

Many studies have reported that the majority of people, including health care workers, do not clean their mobile device. This poses a potential risk factor, as many doctors and nurses not only carry their mobile devices with them, but some have also reported using them while observing patients . The most widely used disinfecting agent for bacterial contamination of cell phones in these studies is $70 \%$ isopropyl alcohol, which works by damaging the bacterial cell membrane and denaturing proteins found in the cytosol . However, recommendations for proper cleaning have not yet been established as many phone manufacturers recommend against using alcohol to clean their phones.

\section{Conclusions}

Mobiles can act as fomites in the transmission of hospital acquired infections. However, further studies have to be carried out to know the genetic relatedness between the organisms isolated from the hands and from the mobiles which offer conclusive proof of their role in the spread of hospital acquired infections.

To prevent the potential spread of infections through mobile phones, training of the health care personnel about strict infection control practices, hand hygiene, environmental disinfection and routine decontamination of mobile phones with alcohol should be advocated to prevent the spread of infection in the hospital settings.

\section{References}

[1]. Annand JW, Bajaj N, Sheth A, Burgess J, Brooke JS. Potential pathogens and effective disinfectants on public telephones at a large urban United States university. Journal of environmental health. 2009;71:24.

[2]. Nikolic M, Arandjelovic M, Stankovic A, Krivokapic L. Bacterial contamination of mobile phones used in hospitals. HEALTHMED. 2011;5:1254-1259.

[3]. Lee YJ, Yoo CG, Lee CT, Chung HS, Kim YW, Han SK, Yim, JJ. Contamination rates between smart cell phones and non-smart cell phones of healthcare workers. Journal of Hospital Medicine. 2013;8:144-147. doi: 10.1002/jhm.2011

[4]. Tunç K, Olgun U. Microbiology of public telephones. The Journal of infection. 2006;53:140-143.

[5]. Abdollahi A, Mahfouzi S. Bacterial contamination of Hospital Telephones. Pakistan Journal of Medical Sciences. 2010;26(3):747750

[6]. Ilusanya OAF, Adesanya OO, Adesemowo A, Amushan NA. Personal Hygiene and Microbial Contamination of Mobile Phones of Food Vendors in Ago-Iwoye Town, Ogun State, Nigeria. Pakistan Journal of Nutrition. 2012;11:276-278.

[7]. Smith SI, Opere B, Goodluck HT, et al. Antibiotic susceptibility pattern of Staphylococcus species isolated from telephone receivers. Singapore medical journal. 2009;50:208.

[8]. Kramer A, Schwebke I, Kampf G. How long do nosocomial pathogens persist on inanimate surfaces? A systematic review. BMC infectious diseases. 2006;6:130-130.

[9]. Borer A, Schlaeffer F, Gilad J, et al. Cell phones and Acinetobacter transmission. Emerging infectious diseases. 2005;11:11601161.

[10]. Visvanathan A, Gibb AP, Brady RRW. Increasing Clinical Presence of Mobile Communication Technology: Avoiding the Pitfalls. Telemedicine journal and e-health : the official journal of the American Telemedicine Association. 2011;17:656-661.

[11]. Brady RRW, Verran J, Damani NN, Gibb AP. Review of mobile communication devices as potential reservoirs of nosocomial pathogens. The Journal of hospital infection. 2009;71:295-300.

[12]. Yusha'u M. Isolation of bacteria and fungi from personal and public mobile cellphones. International Journal of Biomedical and Health Sciences. 2010;6;98-102.

[13]. Peleg AY, Seifert H, Paterson DL. Acinetobacter baumannii: emergence of a successful pathogen. Clinical microbiology reviews. 2008;21:538-582.

[14]. Hedin G (1993), "Staphylococcus epidermidis - hospital epidemiology and the detection of methicillin resistance", Scandinavian Journal of Infectious Diseases Supplementum (Oslo Norway: Scandinavian University Press)

[15]. Otto M. Staphylococcus epidermidis - the 'accidental' pathogen. Nature Reviews Microbiology. 2009;7:555-567.

[16]. Holmes JW, Williams MD. Methicillin-resistant staphylococcus aureus screening and eradication in the surgical intensive care unit: Is it worth it? Am J Surg. 2010;200:827-831.

[17]. Jeske H, Tiefenthaler W, Hohlrieder M, Hinterberger G, Benzer A. Bacterial contamination of anaesthetists' hands by personal mobile phone and fixed phone use in the operating theatre. Anaesthesia. 2007;62:904.

[18]. Ulger F, Esen S, Dilek A, Yanik K, Gunaydin M, Leblebicioglu H. Are we aware how contaminated our mobile phones with nosocomial pathogens? Annals of clinical microbiology and antimicrobials. 2009;8:7-7.

[19]. 4. Goldblatt JG, Krief I, Klonsky T, et al. Use of cellular telephones and transmission of pathogens by medical staff in New York and Israel. Infection Control and Hospital Epidemiology. 2007;28:500-503.

[20]. Wendt C, Dietze B, Dietz E, Ruden H. Survival of Acinetobacter baumannii on dry surfaces. Journal of Clinical Microbiology. 1997;35:1394-1397. 